\title{
THE DIFFERENCE OF QUALITY OF LIFE AND COGNITIVE FUNCTION BETWEEN PATIENTS WITH AND WITHOUT AGE-RELATED MACULA DEGENERATION (AMD)
}

Bobby Kristianto ${ }^{1}$, Anak Agung Ayu Sukartini Djelantik ${ }^{1}$, Ari Andayani ${ }^{1}$, I Gusti Ayu Made Juliari ${ }^{1}$, Anak Agung Mas Putrawati T ${ }^{1}$, Ni Made Ari Suryathi ${ }^{1}$, I Gde Raka Widiana ${ }^{2}$

${ }^{1}$ Departement of ophthalmology, Faculty of Medicine, Udayana University/Sanglah General Hospital, Denpasar, Bali

${ }^{2}$ Departement of Internal Medicine, Faculty of Medicine, Udayana University/Sanglah General Hospital, Denpasar, Bali

\author{
Abstract \\ Introduction: To determine the difference in the quality of life and cognitive function in patients \\ with and without $A M D$.
}

Methods: This research is an observational analytic study, a prospective cross sectional study with independent t-test statistical analysis.

Result: Study samples's total are 66 people selected by consecutive sampling with 33 people in the group with $A M D$, and 33 people in the group without $A M D$ and each sample must filled the National eye institute Visual Function Questionaire (NEI-VFQ) and MMSE Questionaire. The results of the study showed the average age of the group with AMD 68 years and the group without AMD 67 years old. Most of the male sex and residence in denpasar in both groups. Most AMD with the wet type by $60.6 \%$. On the measurement of quality of life, it showed decreasing in all subscale in the group with $A M D$ compared to the group without $A M D$ with total average $27.2 \%$ and also decreasing in cognitive function measured by MMSE in the group of AMD compared to the group of non - AMD with $6.8 \%$, even though the MMSE score of the groups are within normal limits. All these things stated significant differences $(p<0.05)$ statistically.

Conclusion: There are decreasing quality of life and cognitive function in AMD groupd compared to Non-AMD group which is needed more treatment and screening in the future.

Keywords: Age-Related Macula Degeneration,AMD,ARMD,Vitreo-Retina,Macula

Cite This Article: KRISTIANTO, Bobby et al. THE DIFFERENCE OF QUALITY OF LIFE AND COGNITIVE FUNCTION BETWEEN PATIENTS WITH AND WITHOUT AGE-RELATED MACULA DEGENERATION (AMD). International Journal of Retina, [S.I.], v. 4, n. 2, p. 142, sep. 2021. ISSN 2614-8536. Available at: <https://www.ijretina.com/index.php/ijretina/article/view/168>.doi: https://doi.org/10.35479/ijretina.2021.v ol004.iss002.168.

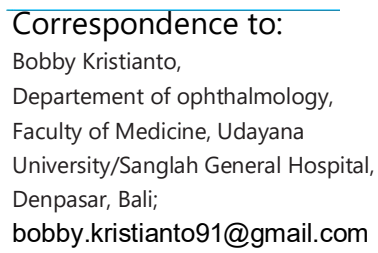

\section{INTRODUCTION}

Age-Related Macular Degeneration (AMD) is the macular disease who can affect loss of central vision for older people.(AAO, 2020)

AMD also as one of world blindness causes with $8.7 \%$. There are two types, dry AMD and Wet AMD which is dry ones is the most common of AMD. (AAO, 2020)

The causes of AMD is still not yet determined but History of smoking and hypertension gives higher risk to become AMD. Main symptoms of AMD are loss of central vision. (AREDS, 2020)

In world, AMD is estimated almost 20-25 million people for suffering and would be 3 times more in the next 30-40 years.(Bhutto, 2014) 
For western countries, AMD has become one of main blindness causes. the incidents are also increasing as getting older. (Bhutto, 2014)

AMD itself could make decreasing quality of life in patients. EQUADE study said that decreasing in all subscale of quality of life in AMD patients and getting worse with increasing severity. Yuzawa et al confirmed that quality of life is decreasing on AMD and increasing with ages.(Matamaros, 2015)

Cognitive Function are important thing when you do daily activity. AMD could make fall out cognitive function. Harrabi et al said that cognitive function in AMD group is lower than control group. Rozzini et al also said difference of cognitive function score betwen AMD group and Non-AMD Group. (Rozzini, 2014)

Decreased quality of life and cognitive function itself can create neurological disorders such as stress, anxiety, dementia and depression. This could be aggravating AMD and the quality of life itself.

In this study, we conducted a study to determine the difference in the quality of life and cognitive function in patients with and without AMD with hyopthesis that there is decreasing in quality of life and cognitive function in AMD group which we hope with this study, we can confirm the previous study result and with this study, we can educate doctor to treat thoroughly with such as cooperation with another department .

\section{METHOD}

This study is a prospective cross-sectional study that conducted at Sanglah General Hospital, Denpasar, Bali. This study also was approved by the Institutional Review Board of Udayana University/Sanglah General Hospital, Denpasar Bali. Informed consent was given upon research doing.

The research are made between October 2020 and December 2020 with total subject 66 and divided into 2 groups ( AMD Group and Non-AMD Group).

The inclusion criteria of patients in this study were all patients with ages more than 49, have complete records with macula $\mathrm{OCT}$ to determine $\mathrm{AMD}$ diagnose, willing to join research and answer quisioneirre completely.

History of cornea disease, optic neuropathy and another retina disease, History of cataract with grading more than 2 (wisconsin grade)/N2C2P1(LOCS 2 Grade) or visual acuity less than $6 / 18$, History of another lens disease, History of cataract operation with complication, History of Retina Laser and Intravitreal injection more than twelve times, History of amblyopia, History of neurologic and physologic were excluded from the study which the list are used, we cited from similar study.

Data were collected including age, gender, residence, underlying disease, AMD type, Visual acuity, History of smoking along with National eye institute Visual Function Questionaire (NEI-VFQ) and MMSE Questionaire.The quality of Life of both groups was assessed using the questionnaire of the National eye institute Visual Function Questionaire (NEI-VFQ), which has been translated. The questionnaire assesses the twelve subscale i.e. general health, vision, pain ocular, activities near future, the activities of the far, social function, mental health, the difficulty of the role, dependence, color vision, peripheral vision. While Cognitive Function was also assessed using questionnaire Mini Mental State Exam (MMSE) indonesian version.

Both of them already been validated using validating test with reliability score $>0.7$.

The characteristics and demo figure features were analyzed with descriptive statistics. For statistical comparison between AMD Group and Non-AMD Group, independet t-test was performed. The statistical analyses were performed using SPSS 16.0 for Windows (SPSS, Chicago, IL).

\section{RESULT}

\section{Characteristic of Samples}

The sample of this study are 66 people selected in a consecutive of the population of all patients who come to the clinic RSUP Sanglah who met the inclusion criteria and exclution.

Table. 1 displays the characteristics of the study sample. 
Table 1. Characteristics Of The Study Samples

\begin{tabular}{|c|c|c|}
\hline Variabel & $\begin{array}{l}\text { AMD } \\
\mathrm{n}: 33\end{array}$ & $\begin{array}{c}\text { Non-AMD } \\
\mathrm{n}: 33\end{array}$ \\
\hline Mean Age (Year),Mean \pm SD & $67,82 \pm 7.63$ & $66.55 \pm 7.90$ \\
\hline \multicolumn{3}{|l|}{ Male } \\
\hline Female & $14(42.4 \%)$ & $15(45.5 \%)$ \\
\hline \multicolumn{3}{|l|}{ Residency, n (\%) } \\
\hline Denpasar & $28(84.8 \%)$ & $30(91 \%)$ \\
\hline Badung & $5(15.2 \%)$ & $3(9 \%)$ \\
\hline \multicolumn{3}{|l|}{ AMD Type, n (\%) } \\
\hline Wet & $20(60.6 \%)$ & - \\
\hline Dry & $13(39.4 \%)$ & - \\
\hline \multicolumn{3}{|l|}{ Hypertension History, n (\%) } \\
\hline Hypertension & $22(66.7 \%)$ & $10(30.3 \%)$ \\
\hline \multicolumn{2}{|l|}{ Smoking Habit, n (\%) } & $23(69.7 \%)$ \\
\hline Smoking & $16(48.5 \%)$ & 15 ( 45.5\%) \\
\hline \multicolumn{2}{|l|}{ Visual Acuity (in 6 meter) } & $18(54.5 \%)$ \\
\hline Best & $6 / 9$ & $6 / 6$ \\
\hline Worse & $1 / 300$ & $6 / 12$ \\
\hline
\end{tabular}

The difference in the quality of life and cognitive function between patients with and without AgeRelated Macula Degeneration

The results of this study showed there was a significant difference $(p<0.05)$ between the two groups in each of the subscales and decreasing in all aspect quality of lifes in AMD group. The significant difference $(p<0.05)$ was also present at the examination of cognitive function with the MMSE between the two groups and also decreasing in cognitive function in AMD group even in little differences. Graphic. 1 displays the result.

\section{DISCUSSION}

\section{Characteristic of Samples}

AMD is an eye disease degeneration which became the cause of blindness in the world today. It is also recognized by the WHO that AMD became a cause of blindness no. 4 in the world by $8.7 \%$. In Indonesia itself, there is no exact data about the incidence, prevalence and morbidity of AMD until now. One of the research of the Faculty of Medicine, University of Indonesia period March 2008 January, 2009 against 1259 responder found the prevalence of AMD reached $4.3 \%$. The prevalence of AMD is increased as like as increasing age (National Eye Institute, 2019; The Indonesian Ministry Of Health, 2014; Tany, 2016).

In this study, the average age of the group with AMD 68 years and the group without AMD 67 years old. This result is in accordance with the national eye institute that AMD occurs at the age of 60 or more years old and Also did not much different with the prevalence of Deloitte Macular Degeneration Foundation that AMD is increased at the age of 65 years. On research in Indonesia by Tany,et al (2016) gives result that average age on their research between 60-70 years old, same result as Akhmad et al. and Singare et al research. Wong et al also stated the same thing (Akhmad, 2015; Singare, 2015; Wong, 2014). 


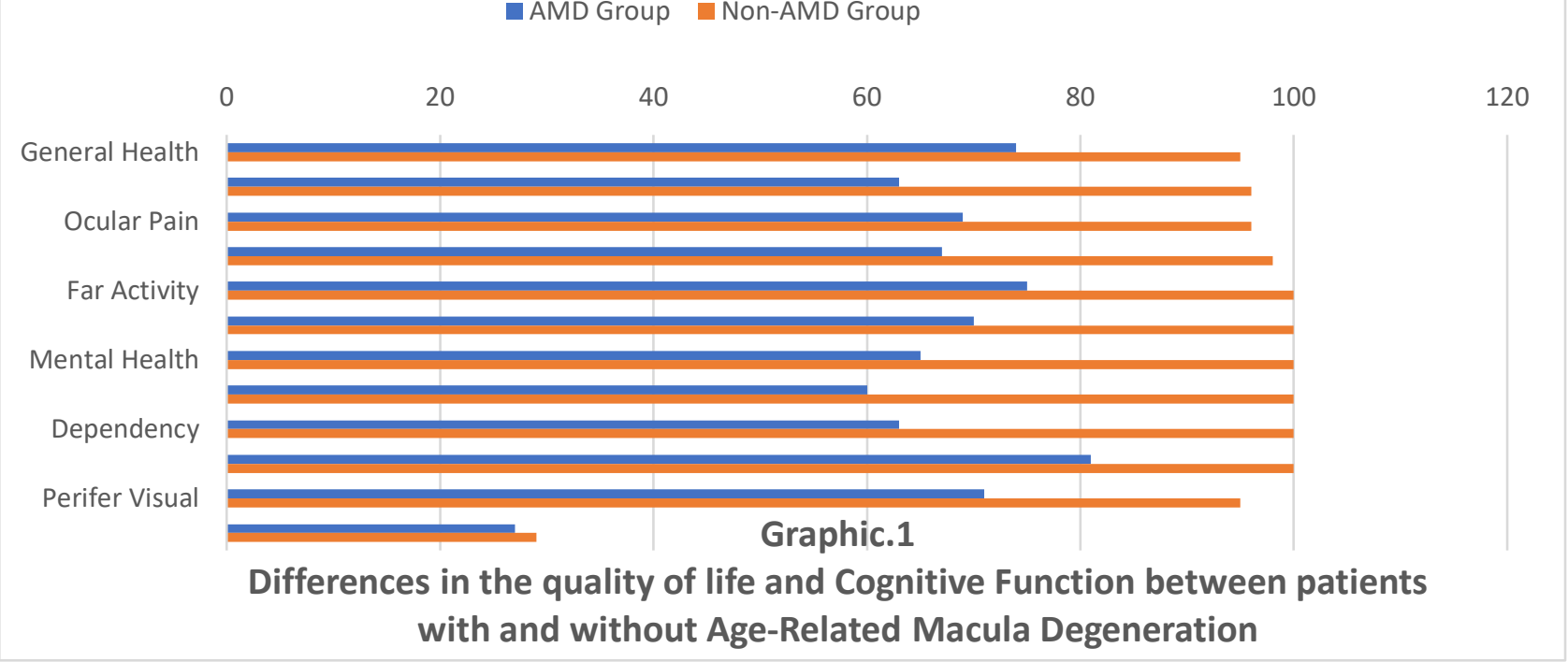

Some research, likely that done by chungmin et al (2014), Xiang li et al (2014) said that more women suffer from AMD (Chung-min, 2014; Xiang li, 2014). Research in Indonesia by Tany,et al also gives result in line with other research by singare et al showed women more than men in incident of AMD (Tany, 2016; Singare, 2015). But also there are several theories as laitinen et al and Chakravarthy et al said that gender is not be influenced in the incidence of AMD. In this study indicates that prevalence of men more than the women in both groups (with AMD and without AMD) (laitinen, 2010; Chakravarthy, 2010).

Based on the diagnosis of the type of AMD is obtained that patient with wet AMD are common, as many as $60,6 \%$. For dry AMD only achieved as much as to 39.4 $\%$. The results of this study differ with the opinion of the llyas and Yulianti, as well as the American Optometric Association, which wrote that AMD dry is found in many patients diagnosed with $A M D$ as many as $70-90 \%$ compared to AMD wet that only $10 \%$ ( Sidarta llyas, 2014).

At the Level of Visual Acuity, this research shows that in visual acuity varied from $6 / 9$ to $1 / 300$ and also judging from the degree of severity of AMD itself. At some text book such as AAO, kanski revealed that the visual acuity worsened along with the worsening degrees of AMD itself. Falkenstein et al stated that the average patient vision AMD is the $6 / 45$ with a range of $6 / 9$ to $<3 / 60$ (Falkenstein, 2008).

\section{The difference in the quality of life and cognitive function between patients with and without Age-Related Macula Degeneration}

Worsening of AMD and Success of a therapy for AMD is strongly associated with adherence and psychological state of the patient itself. AMD even if caused by the age of a threat occurrence of blindness and has already become one of the causes of blindness in the world. Aspects of quality of life and cognitive function for daily life impacted heavily on AMD patients (Yuzawa, 2013; Rozzini, 2014).

The questionnaire NEI-VQF 25 is a tool that can help to make an assessment on the quality of life of the AMD itself (Matamoros, 2015). 
MMSE also a tool that gives an overview of cognitive function in patients with AMD (Larner, 2015). Both of those things can help us to early diagnose if there is a loss of quality of life and cognitive function itself.

The results of this study showed the difference score of the subscale on the quality of life where there is a reduction in score in the group with AMD with the average of $27.2 \%$ compared with the group without AMD. It also shows the difference was statistically significant. Decreasing scores in the group with AMD compared to the group without AMD is the score of the subscale general health with $21.5 \%$, and the sight of the public with $34.5 \%$, pain ocular where $28,2 \%$, the near activity $31.7 \%$, far activity with $25 \%$, social function with $29.8 \%$, mental health $35 \%$, the difficulty of the role is quite large with $40.5 \%$, the dependence of the reach $36.9 \%$, color vision with $18.9 \%$, peripheral vision with a $24.8 \%$.

It is also in accordance with the EQUADE study (matamaros, 2015) that in the study they showed a decrease in scores on all subscale of the questionnaire NEI-VFQ 25 for quality of life. It is also in accordance with that described in Yuzawa et al where on AMD provides the decline of quality of life and as a worsening of AMD providing quality of life are more worsening.

In general, Yuzawa et al and matamaros et al also explained the decreasing presence of the quality of life can cause anxiety and cause a severe mental disorder such as stress and depression. The level of stress and anxiety that excess in patients with AMD are also described can increase the degree of AMD itself. This is explained on the abokyi et al where on the animal model showed oxidative stress high provides an more severity on AMD (Abokyi, 2020).

Besides, it is also influential to measure the success of therapy to everyday life and also help whether or not to use low vision aid. It can also define and give advice to the family as to whether caregiver needs on the patient.

On cognitive function, this study stated that there is a decline of cognitive function in a group with AMD in the form of $6.8 \%$ with The result's score of MMSE in the group with AMD is 27 compared to the group without AMD, namely 29 but indegree score, it is still within normal limits. It is mentioned in the study harrabi et al, where a score of cognitive function were lower in AMD patients,fuchs dystrophy and glaucoma.

Meanwhile, according to rozzini et al mentioned a decrease in the scores of cognitive function with MMSE i.e. a score of 27 compared to the control 28 however, according to the degree of the score was still within normal limits (Rozzini, 2014).

The need for measurement of early cognitive function be able to prevent or diagnose disease early dementia in patients. This is necessary because dementia can worsen the quality of life of the patient itself which will create a vicious circle in the progression and treatment of AMD. Shi rong et al also stated the presence of the association of dementia with deterioration and increased risk occurance of AMD (Shi-Rong, 2019). 


\section{CONCLUSION}

Conclusion in this study is the presence of significant differences and a decrease in quality of life in the group with AMD by $27.2 \%$ compared to the group without AMD. Significant differences and a decrease was also seen in the study with the assessment of cognitive function in a group with AMD by $6.8 \%$ compared to the group without AMD. The need for measurement of early cognitive function and quality of life would be able to prevent or diagnose neurological disease such as strees, anxiety, dementia and depression that would make severity proggresion of AMD.

\section{LIMITATION}

The weaknesses of this research are there is a risk occurs recall bias because of the use of the questionnaire and because of the research done in the middle of the pandemic covid, this can affected psychological and mental level of the subject.

\section{REFERENCES}

1. Abramoff and Kay. 2013. Image Processing. Optical Imaging Technologies. 6(1). 151-176.

2. Abokyi, S. et al. 2020. Review Article: Central Role of Oxidative Stress in Age Related Macular Degeneration: Evidence from a Review of the Molecular Mechanisms and Animal Models, Journal of Hindiawi.

3. Age-Related Eye Disease Study Research Group.2006. The Age-Related Eye Disease Study (AREDS): Design Implications AREDS Report No. 2. National Eye Institute.

4. American Academy of Ophthalmology and Staff. 2019. BCSC: Vol.2 Fundamentals and Principal of Ophthalmology. American Academy of Ophthalmology.

5. American Academy of Ophthalmology and Staff. 2019. BCSC: Vol.11 Retina and Vitreous. American Academy of Ophthalmology.

6. Bhutto,I. Lutty,G. 2012. Understanding Agerelated Macular Degeneration (AMD). Molecular Aspects of Medicine. 33. p295-317.
7. Chakravarthy,U. Wong, Y. Fletcher, A. et al. 2010. Clinical risk factors for age-related macular degeneration: a systematic review and meta-

analysis.BioMedCentral.Availablefrom:http:// bmcophthalmol.biomedcentral.c om/articles/10.1186/1471- 2415-10-31

8. Chung min, et al. 2014. Prevalence, Racial Variations, and Risk Factors of Age-Related Macular Degeneration in Singaporean Chinese, Indians, and Malays. ElSevier. available from www.aaojournal.org.

9. Cheier,J. Jefferys,J.Singerman,L. Solomon,S. 2012. Detection of New- Onset Choroidal Neovascularization Using Optical Coherence Tomography The AMD DOC Study. Ophthalmology: 119(4).p771-77.

10. Dougherty, B. et al. 2010. Comparison of Scoring Approaches for the NEI VFQ-25 in Low Vision. Journal of Optometri and Vision Science: Vol. 87(4). p543-548.

11. Dougherty, B. et al. 2017. Measurement of Perceived Stress in Age-Related Macular Degeneration. Journal of Optometri and Vision Science: Vol. 94(3). p290-296.

12. Elvioza et al.2015. Prevalensi dan Karakteristik Faktor Risiko Pada Kejadian Age Related Macular Degeneration di Jakarta Timur. [cited 2015 September20].Available from:

http://mru.fk.ui.ac.id/index.php?uPage $=$ profi I.profil detail\&smod $=$ profil\&sp $=$ public\&idp \%20enelitian $=1498$

13. Falkenstein,l. et al. 2008. Comparison of Visual Acuity in Macular Degeneration Patients Measured with Snellen and Early Treatment Diabetic Retinopathy Study Charts. NIH Journal of Ophthalmology. 115(2): p319-323.

14. Friedman,D. O'Colmain,B. Muñoz,B. 2004. Prevalence of Age- related Macular Degeneration in the United States. Archives of Ophthalmology. 122(4). p564-572. 
15. Hanafi, M. Hijazi, A. Coenen, F. and Zheng, Y. 2010. Retinal image Classification for the Screening of Age-related Macular Degeneration. In: SGAI International Conference on Artificial Intelligence Al-2010. p325-338.

16. Harrabi, H. et al. 2014. Clinical and Epidemiologic Research: Age-Related Eye Disease and Cognitive Function. Invest Ophthalmol Vis Sci. 56. p1217- 1221.

17. Jager,R. Mieler,W. Miller,J. 2008. Age-related Macular Degeneration. N. Engl. J. Med. 358(24). p2606-2617.

18. Jefferis, J. et al. 2012. The impact of visual impairment on Mini-Mental State Examination Scores in the Newcastle 85+ study, Journal of Age and Ageing vol. 41. p565-568.

19. Kanagasingam,Y. Bhuiyan,A. et al. 2014. Progress on Retinal Image Analysis for Agerelated Macular Degeneration. Prog. Retin. Eye Res. 38. p20-42.

20. Kanski, J.J. 2012. A Synopsis of Clinical Ophtalmology. Second Edition.United Kingdom: Elsevier. p.304-306

21. Khurana, AK. 2007. Comprehensive Ophthalmology: Fourth Edition.India : New Age International Publisher.

22. Laitinen, $A$. Laatikainen, L. Härkänen, $T$. Koskinen,S. Reunanen,A. Aromaa,A. 2010. Prevalence of major eye diseases and causes of visual impairment in the adult Finnish population: a nationwide population-based survey. Acta Ophthalmol ;88: p463-471.

23. Larner,A. 2015. Six-item Cognitive Impairment Test: suitable for the visually impaired?. Progress in Neurology and Psychiatry Journal. Kementrian Kesehatan RI. 2014. Infodatin Pusat Data dan Informasi Kementrian Kesehatan RI. Kementrian kesehatan RI. Jakarta.

24. Matamoros,E. et al. 2015. Quality of Life in Patients Suffering from Active Exudative
Age-Related Macular Degeneration: The EQUADE Study. Ophthalmologica Journal vol. 234. p151-159..

25. Mookiah,M. R. K. Acharya,U. R. Koh,J. E. et al. 2014. Automated Diagnosis of Age-related Macular Degeneration using Greyscale Features from Digital Fundus Images. Computers in Biology and Medicine. 53. p5564.

26. Morton,R. F. Hebel,J. R. McCarter,R. J. 2009. Terjemahan Bahasa Indonesia: Panduan Studi Epidemiologi dan Biostatistika. EGC.

27. National Eye Institute. Prevalence of adult vision impairment and Age- related eye diseases

in

America.https://nei,nih.gov/eyedata/adultvis ion_usa, 20 Januari 2019.

28. Pennington $\mathrm{KL}$, et al. Epidemiology of agerelated macular degeneration (AMD): associations with cardiovascular disease phenotypes and lipid factors. Eye and Vision Journal 2016 3:34.

29. Rong,S.S. et al. 2019. Comorbidity of dementia and age-related macular degeneration calls for clinical awareness: a meta- analysis, British Journal of Ophthalmology: Vol. 19(0). p1-7.

30. Rozzini,L. 2014. Cognitive Dysfunction and Age-Related Macular Degeneration, American Journal of Alzheimer's Disease \& Other Dementias Vol. 29(3). p256-262.

31. Ryan, S. et al. 2017. Ryan's Retina: 6th Edition. ELSevier.

32. Sidarta Ilyas,HS. Yulianti,SR. 2014. Mata Tenang Penglihatan Turun Perlahan. IImu Penyakit Mata (5th ed).FKUl; p239-40.

33. Singare,R. Deshmukh,S. Ughade,S.N. Thakre,S. 2015. Age - Related Macular Degeneration: Prevalence and Risk factors in elderly population (Aged > 60 years) in Central India. International Journal of Scientific and Research Publications;5: p2 
34. Sjahrir,H. Ritarwan,K. Tarigan,S. Rambe,A.S. Lubis,I.D. Bhakti,I. The Mini Mental State Examination in healthy individuals in Medan, Indonesia by age and education level. Neurol J Southeast Asia.2001;6: p19-22.

35. Tany,C.E. et al. 2016. Prevalensi age related macular degeneration di Poliklinik Mata BLU RSUP Prof. Dr. R. D. Kandou Manado periode Januari 2013 - Oktober 2015. Jurnal eClinic(eCl). Vol. 4. No.1.

36. Wong,W.L Su,X. Li,X. Cheung,C.M. Klein,R. Cheng,C.Y. et al. 2014. Global prevalence of age-related macular degeneration and disease burden projection for 2020 and 2040: a systematic review and meta-analysis. Lancet Glob Health;2: pe106-e116.
37. Xiangli, et al. 2012. Prevalence and Risk Factors for Age-Related Macular Degeneration in Indians: A Comparative Study in Singapore and India.Elsevier Inc. Avaliable from AJO.com.

38. Yuzawa,M. Fujita,K. Tanaka,E. Wang,E.C. 2013. Assesing quality of life in the treatment of patients with age-related macular degeneration: clinical research and recommendations for clinical practice, Clinical Ophthalmology Journal vo.7. p13251332

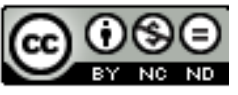

This work licensed under Creative Commons Attribution 